Motrivivência $\quad$ v. 27 , n. 46, p. 69-83, dezembro/2015

\title{
A PRODUÇÃO CIENTÍFICA NO CBCE/CONBRACE: a formação continuada de 2007 a 2013 em foco
}

\author{
Deiva Mara Delfini Batista? \\ Deisy de Oliveira Silva ${ }^{2}$ \\ Amauri Aparecido Bássoli de Oliveira ${ }^{3}$ \\ leda Parra Barbosa Rinaldi ${ }^{4}$
}

\section{RESUMO}

O presente trabalho, de cunho qualitativo e caráter documental, objetivou analisar a produção científica sobre formação continuada de professores entre os anos de 2007 e 2013, a partir do GTT "Formação de Professores e Mundo do Trabalho" do Colégio Brasileiro de Ciências do Esporte. Identificou-se 49 trabalhos sobre a temática, os quais foram categorizados em diferentes grupos, a partir de suas abordagens e características. Os resultados obtidos retratam a existência de produção científica sistemática sobre a formação continuada, e que esta se encontra articulada com a realidade da pós-graduação brasileira. Contudo, algumas categorias não demonstraram grande representatividade, apontando desafios a serem enfrentados, carecendo de maior investigação sobre a temática.

Palavras-chave: Formação Continuada; Educação Física; Conhecimento; Trabalho

1 Mestre em Educação. Professora Assistente da UEM, Maringá/Paraná, Brasil: E-mail: dmdbribeiro@uem.br

2 Mestranda em Educação Física. UEM, Maringá/Paraná, Brasil: E-mail: deisyoliveira14@gmail.com

3 Doutor em Educação Física. Professor Associado da UEM, Maringá/Paraná, Brasil.

E-mail: amauribassoli@gmail.com

4 Doutora em Educação Física. Professora Associada da UEM, Maringá/Paraná, Brasil.

E-mail: parrarinaldi@hotmail.com 
CONSIDERAÇÕES INICIAIS: DA FUNDAMENTAÇÃO TEÓRICA À PROBLEMATIZAÇÃO

Nos últimos trinta anos, no Brasil, a temática sobre a formação de professores/ profissionais da educação tem sido alvo de debates entre estudiosos, tanto no contexto acadêmico quanto no de políticas públicas, das entidades sindicais e associações representativas da categoria docente.

Há um consenso entre tais estudiosos de que as reformas educativas que vêm acontecendo em nosso país objetivam adequar o sistema educacional ao processo de reestruturação produtiva frente à internacionalização do capital e globalização da economia, imprimindo uma forte concepção mercadológica de educação, refletindo a dependência das políticas de Estado e educação aos organismos internacionais tais como BIRB/Banco Mundial e FMI (ANFOPE, 2010, 2012; SGUISSARDI, 1998; FRIGOTTO, 2008; FREITAS, 2002, 2007, SILVA JÚNIOR, 2002).

Historicamente, desde o final da década de 1970 e início da de 1980 no movimento da democratização da sociedade, a luta dos educadores trouxe a necessidade de um novo olhar para o fenômeno educativo, levando em conta as determinações entre educação e sociedade, seus objetivos e a forma como a escola se organiza buscando romper com a ótica tecnicista predominante até então no pensamento educacional (FREITAS, 2002). Buscou também a valorização dos professores, tomada pela concepção de profissional da educação como aquele que tem na docência e no trabalho pedagógico a sua particularidade e especificidade.

A produção acadêmica realizada no âmbito das universidades, impulsionada pela criação dos cursos de pós-graduação articulando diferentes áreas do conhecimento, contribuiu para a análise crítica da realidade educacional brasileira evidenciando o caráter ideológico da educação. Por outro lado, passou a ser compreendida como um espaço de contradições, abrindo caminhos para recolocá-la, assim como a formação de professores, a escola, a valorização e profissionalização da categoria em questão.

Todavia, nos anos 1990, denominados de "Década da Educação" (FREITAS, 2002, 2007) percebeu-se um refluxo deste pensamento emancipador de educação mediante a subordinação/recomendação dos organismos internacionais, e a qualidade da educação passou a ser atrelada às demandas da globalização econômica exigindo recursos humanos qualificados.

Para Gatti (2008), na década do início dos anos 2000, vivemos o paradoxo da formação de professores, qual seja o mundo do trabalho pressionando para um novo modelo informatizado adquirido pelo conhecimento (chamada hoje, por alguns, de sociedade do conhecimento) e, por outro lado, a constatação dos precários desempenhos escolares de grandes parcelas da população. Na análise da autora, nos documentos do Banco Mundial (1995, 1999, 2002) de forma ampla, fica clara a necessidade de preparar os professores para formar as novas gerações, para a "nova" economia mundial, bem como é enfatizado um papel renovador para a formação continuada.

No Brasil, a promulgação da Lei 5692/71 na Lei de Diretrizes e Bases já apontava, embora sem muita clareza, para a necessidade de formação continuada de professores, quando no artigo 38 destacou-se "o aperfeiçoamento e atualização constante dos professores e especialistas da Educação" 
e, no artigo 43 mencionou que recursos públicos seriam destinados entre outras para "a melhoria progressiva do ensino, o aperfeiçoamento e a assistência ao magistério e aos serviços da educação". Daí por diante, outros marcos legais importantes quanto à formação continuada no país se destacam, bem como na Constituição Brasileira de 1988 (Art. 214, Inciso IV), em 1996 por meio da Lei 9.394/96 da Lei de Diretrizes e Bases (Art. 3, Inciso VII; Art. 61, Inciso I; Art. 63, Inciso III; Art. 67, Inciso II), em 2001 por meio da Lei 10.172/2001 e, mais recentemente, a Lei 12.796 de 2013 alterou o parágrafo único disposto no Artigo 62 da LDB de 1996, que trata da formação continuada, ficando assim designada: "Garantir-se-á formação continuada para os profissionais a que se refere o caput, no local de trabalho ou em instituições de educação básica e superior, incluindo cursos de educação profissional, cursos superiores de graduação plena ou tecnológica e de pósgraduação" (BRASIL, 2013).

De uma forma ou de outra, percebe-se que as temáticas educação e formação de professores ganharam espaço nos documentos legais e nas pesquisas científicas e, seguindo o movimento mundial de reformas educacionais, acolheram experiências e perspectivas de pesquisadores estrangeiros, como os de Portugal (NÓVOA, 1992), da Espanha (SACRISTÁN; PÉREZ GOMÉZ, 1998; MARCELO GARCÍA, 1999); dos Estados Unidos (ZEICHNER, 1993; SCHÖN, 2000) e do Canadá (TARDIF, 2002). No Brasil, muitos estudos contribuíram com o debate sob diferentes perspectivas, dentre eles os estudos de Pimenta e Ghedin (2002), Candau (1997), Silva Júnior (2002), Dourado (2001, 2007) Kuenzer (1990), Fazenda (2004) dentre outros, além de dissertações, teses e artigos veiculados nas principais revistas científicas do país. Nestes contextos, encontram-se várias concepções de professor tais como: professor reflexivo, investigador na ação, indagador, pedagogo radical, pesquisador de sua prática, intelectual crítico, intelectual crítico e reflexivo, prático-reflexivo, reflexivo-crítico, reflexivo-dialético, intelectual crítico-transformador e outros.

Grosso modo, os estudos procuram responder a uma necessidade histórica de romper com a perspectiva da racionalidade técnico-instrumental que tem fundamentado práticas pedagógicas acríticas e reprodutivistas (SAVIANI, 1987). No entanto, há uma alerta dentre estes estudiosos no que diz respeito à centralidade na figura do professor, do conteúdo, da escola e/ou na sala de aula na categoria da prática, ou seja, que individualiza a responsabilidade da qualidade da educação e que, de forma restritiva, "desconsidera a influência da realidade social sobre as ações e pensamentos e sobre o conhecimento como produto de contextos sociais e históricos" (PIMENTA, 2002, p. 24).

Este contexto legal vem apontando a importância atribuída à formação continuada de professores, bem como as demandas para o atendimento a este segmento. A partir destas considerações, o modo como a temática vem sendo tratada nos trabalhos apresentados no Congresso Brasileiro de Ciências do Esporte (CONBRACE/CONICE/ $\mathrm{CBCE}$ ) se concretiza como a questão norteadora do presente estudo.

A área da Educação Física como prática social e pedagógica sofreu/sofre as influências destas problemáticas e, preocupada com os rumos da educação no Brasil e a par das questões legais, das teorias 
educacionais, pedagógicas, científicas e dos movimentos sociais procura, por meio de estudos, contribuir no processo educacional, nos debates acadêmicos e nos avanços desta área do conhecimento.

Nesse sentido, este trabalho teve como objetivo analisar a produção científica sobre formação continuada nos trabalhos apresentados no CBCE no período de 2007 a 2013, focalizando o Grupo de Trabalho Temático "Formação Profissional e Mundo do Trabalho", a fim de mapear como estes têm sido abordados. Para tanto, foi necessário realizar um levantamento acerca dos trabalhos sobre formação continuada no período citado; selecionar títulos e resumos dos mesmos; verificar seus conteúdos, categorizá-los e analisá-los.

A pesquisa é do tipo documental (MARCONI; LAKATOS, 2003), cuja principal característica é a utilização de documentos como fonte primária. A coleta de dados se deu a partir dos trabalhos apresentados nos congressos, disponibilizados pelo site do CBCE para o acesso público. A escolha da fonte se deu por se tratar de uma entidade científica que congrega pesquisadores ligados à área de Educação Física/Ciências do Esporte e promove, com periodicidade bienal, o Congresso Brasileiro de Ciências do Esporte (CONBRACE) e o Congresso Internacional de Ciências do Esporte (CONICE), considerados dois dos maiores eventos dentre as sociedades científicas.

O congresso apresenta instâncias organizativas denominadas Grupos de Trabalhos Temáticos (GTTs), responsáveis por serem polos aglutinadores de pesquisadores com interesses comuns em temas específicos. Para este trabalho, focamos o GTT "Formação Profissional e Mundo do Trabalho" por englobar estudos distintos acerca do processo profissional concernentes à área de conhecimento Educação Física. A escolha pelo início em 2007 se deu de forma intencional, por ser o período em que os documentos oficiais se tornam mais explícitos em relação à formação continuada. Utilizou-se inicialmente para a filtragem dos dados, o título e o resumo dos trabalhos e, em casos de insuficiência de clareza, realizamos a leitura completa dos mesmos, para posterior elaboração das categorias e análises.

\section{A produção científica sobre formação con- tinuada no CBCE (2007-2013): das análises}

Adotamos a expressão formação continuada a partir do entendimento de continuidade da formação profissional, processo de construção permanente do conhecimento que proporciona novas reflexões acerca da ação profissional, desenvolvimento e aprimoramento do trabalho pedagógico (ANFOPE, 2010, 2012) e que, articulada à formação inicial e a condições de trabalho, salário e carreira se faz uma das dimensões importantes para a materialização de uma política global para o profissional da educação, conforme assevera Freitas (2002). Para melhor exposição dos dados, a Tabela 1 representa o resultado encontrado no período pesquisado. 
Tabela 1 - Total de trabalhos publicados no GTT Formação e Mundo do Trabalho do ano de 2007 a 2013 e total de trabalhos publicados sobre Formação Continuada.

\begin{tabular}{cccc}
\hline Ano & $\begin{array}{c}\text { Total de trabalhos } \\
\text { no GTT }\end{array}$ & $\begin{array}{c}\text { Trabalhos sobre } \\
\text { formação continuada }\end{array}$ & Percentual (\%) \\
\hline $\mathbf{2 0 0 7}$ & 38 & 08 & $21 \%$ \\
$\mathbf{2 0 0 9}$ & 58 & 10 & $17 \%$ \\
$\mathbf{2 0 1 1}$ & 89 & 19 & $21 \%$ \\
$\mathbf{2 0 1 3}$ & 72 & 12 & $17 \%$ \\
TOTAL & 257 & 49 & $19 \%$ \\
\hline
\end{tabular}

Observa-se que o número total de trabalhos que tratam sobre a temática formação continuada corresponde a $19 \%$ do total de trabalhos publicados no referido GTT no período pesquisado, e que o número de trabalhos produzidos aumentou nos eventos entre 2007 a 2011, tendo um ligeiro retrocesso em 2013, sendo que os trabalhos específicos sobre a formação continuada seguiram a mesma lógica, proporcionalmente. Detectou-se ainda que, dentre os 49 trabalhos, apenas 1 se refere à outra área de conhecimento humano que não a Educação Física.

Por outro lado, considerando a proporção das produções sobre formação continuada em relação ao total de trabalhos publicados no GTT, especificamente por edição do congresso, percebe-se uma oscilação nos percentuais relativos, haja vista que em 2007 os trabalhos sobre formação continuada representaram $21 \%$ das publicações totais do GTT, em 2009 representaram $17 \%$ e, coincidentemente, o mesmo ocorreu em 2011 e 2013, respectivamente. Nesse sentido, apesar das publicações terem aumentado quantitativamente e de forma gradativa ao longo das edições do $\mathrm{CBCE}$, nota-se que este aumento não se deu de forma linear em relação à quantia total de publicações no GTT.

Sendo assim, compreende-se que, embora num primeiro momento os dados apontem uma melhora aparentemente considerável, o número de estudos sobre formação continuada não tem grande representatividade, tanto se analisado num todo como se por edição específica. Isso nos remete a pensar que, apesar da formação continuada ser considerada como uma das dimensões importantes para que se materialize uma política global para o profissional da educação, talvez ainda falte um esforço por parte dos pesquisadores educacionais de se aprofundar e discutir sobre a temática. Contudo, sabemos que não necessariamente isso implica na qualidade das pesquisas e, ainda que os números apontem carência de estudos de formação continuada, sobretudo na área da Educação Física, estas podem apontar conteúdos relevantes e essenciais para o quadro da educação brasileira, servindo como exemplo e embasamento para a atuação dos professores nas escolas bem como para outros estudos.

Por se tratar de um evento nacional realizado bienalmente em diferentes partes do território brasileiro, tomamos como 
ponto de partida para a categorização dos dados, a regionalidade das produções acerca da formação continuada, conforme o Gráfico 1, que segue.

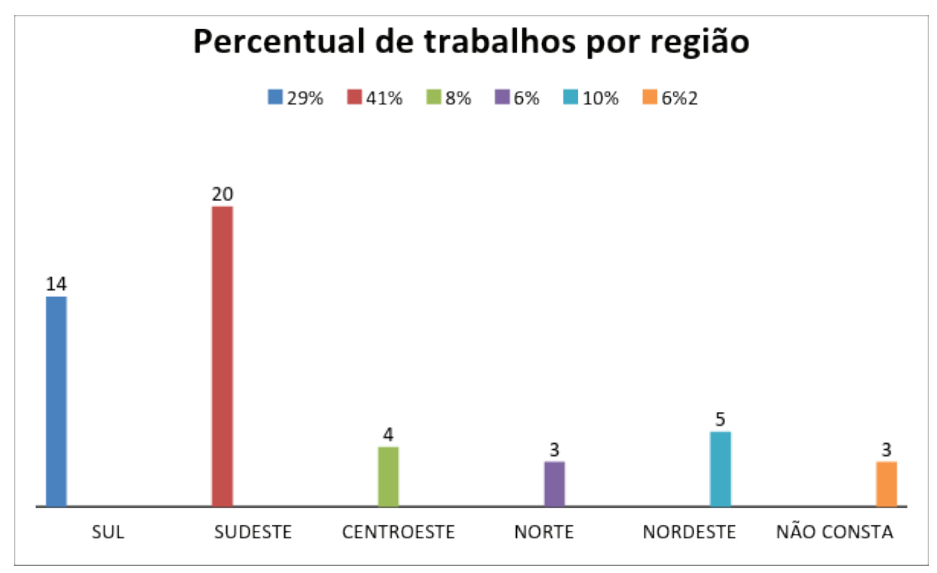

Gráfico 1 - Categoria geral dos Trabalhos sobre Formação Continuada representados por regiões do Brasil.

Primeiramente, cabe ressaltar o local de realização das edições do evento, sendo: 2007 em Recife (PE), 2009 em Salvador (BA), 2011 em Porto Alegre (RS) e em 2013 em Brasília (DF). Observaram-se 15 Estados brasileiros representados, apontando que a maior concentração de trabalhos envolvendo a temática em questão se deu na região Sudeste (41\%), seguida da região Sul (29\%), região Nordeste $(10 \%)$, região Centro-Oeste $(8 \%)$ e região Norte $(6 \%)$, de modo que $6 \%$ dos trabalhos não constavam a região a qual pertenciam.

Para a realização da análise, considerou-se a princípio as publicações com a proximidade geográfica em relação ao local de realização do evento, supondo uma possível relação. Entretanto, tal hipótese não foi confirmada e os dados parecem demonstrar uma vinculação com a pós-graduação do país.
De acordo com os dados da CAPES (2013), o maior número de cursos de pós-graduação reconhecidos estão na região Sudeste (2.726), seguido pela região Sul (1.151), Nordeste (1002), Centro-Oeste (423) e região Norte (255), corroborando com o levantamento deste estudo. Estes dados também remetem à problemática evidenciada em pesquisas sobre a necessidade de uma distribuição mais homogênea dos cursos de pós-graduação no território nacional, reivindicação já antiga das regiões nordeste, norte e centro-oeste, para a produção, disseminação e universalização do conhecimento (TAFFAREL 2007, BIANCHETTI, 2009), bem como nos diversos trabalhos constantes na edição de 2003 da Revista Brasileira de Ciências do Esporte.

A realidade destes fatos é condizente ainda a um plano maior que diz respeito ao desenvolvimento econômico-social do 
Brasil, continua um país de desenvolvimento desigual, de maior concentração econômica, de infraestrutura, serviços e população nas cidades do Sudeste (SILVA JÚNIOR; SPEARS, 2012).

No entanto, importante destacar que, dos 49 trabalhos pesquisados, as abordagens de cunho qualitativo foram predominantemente contempladas, de modo que apenas um trabalho eminentemente quantitativo foi evidenciado no levantamento. As pesquisas descritivas lideraram com $20 \%$, seguida das documentais $(14 \%)$, relatos de experiências (10\%) e bibliográfica, com $8 \%$. Pesquisas do tipo etnográficas, de grupo focal, pesquisa-ação, estudo de caso, crítica e participante também foram identificadas, porém não significativamente. Dentre as documentais, as análises de banco de dados chamaram atenção, refletindo a necessidade de mapeamentos, bem como a contribuição destes estudos para os demais pesquisadores.

A predominância qualitativa das pesquisas reflete a realidade educacional brasileira que, desde os anos de 1980, tem utilizado tais abordagens para suprir a necessidade de compreender os fenômenos sob outras perspectivas que não somente as quantitativas, mas que, no entanto, não dispensasse a rigorosidade como em qualquer trabalho de investigação científica em termos epistemológicos, ontológicos, teleológicos ou metodológicos. A educação nesta perspectiva pode ser melhor compreendida, pesquisada e analisada por captar a realidade e a apreensão dos fenômenos pela visão dos pesquisadores (LÜDKE, ANDRÉ, 1986; MINAYO, 1994, MOLINA NETO; TRIVINÕS,1999).

$E$, quanto ao rigor científico, outro dado relevante diz respeito à sua insuficiência. Assim como já citado em relação aos títulos e resumos, também encontramos trabalhos que não apresentam clareza em seu encaminhamento metodológico $(22 \%)$, cabendo-nos ressaltar quão imprescindível é tornar visível a base teórico metodológica das pesquisas, conferindo-lhes maior cientificidade e fidedignidade.

Além do mais, considerando a existência de trabalhos que não informam a região territorial na qual se deram, destacamos ainda outras questões relevantes que dizem respeito à clareza dos títulos e dos resumos, bem como aos próprios dados identificadores dos autores, de suas respectivas instituições e/ou da localidade (regional) na qual o estudo foi realizado, haja vista que estes dados podem influenciar nos resultados de pesquisas que consideram e analisam metodologicamente estes aspectos.

Outras categorias puderam ser constituídas considerando suas características temáticas, como demonstrado no Gráfico 2 a seguir. 


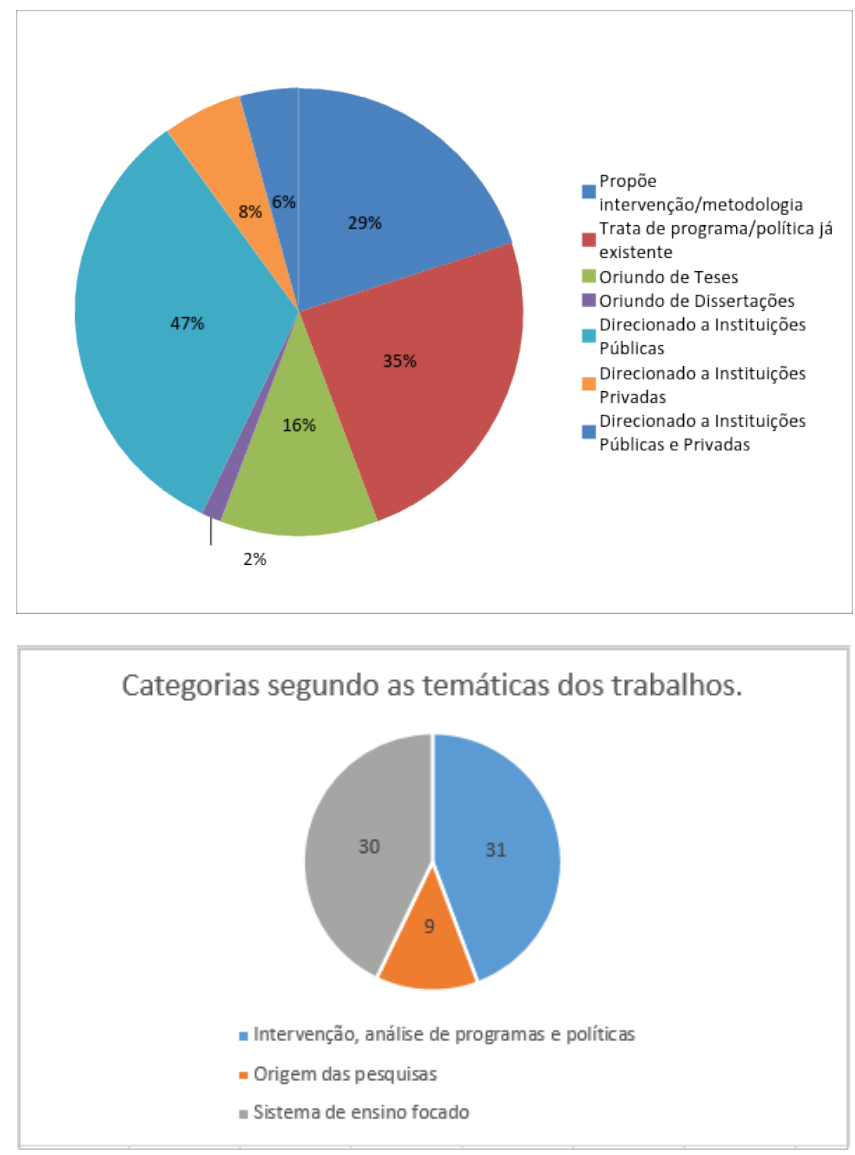

Gráfico 2 - Categorias segundo as temáticas dos trabalhos.

Primeiramente, cabe esclarecer que nos dados apresentados, alguns trabalhos estão contemplados em mais de uma categoria.

Em relação à categoria 1 "Origem das Pesquisas", pode-se identificar que do total de 49 trabalhos, 8 são oriundos de teses e 1 de dissertação. Tal realidade nos parece paradoxal, visto que o período pesquisado apresenta marcos legais e teóricos que problematizam a formação continuada de professores e apontam uma necessidade de estudos mais sistematizados.

Sobre o assunto, autores como Günther e Molina Neto (2000), Andrade Filho (2001), Taffarel (2007), Sánchez Gamboa et al. (2007), Bianchetti (2009) e Bracht (2012) vêm tecendo suas análises, advertindo que o perfil das universidades e o profissional nela formado devem ter o compromisso com projetos de formação científica, pedagógica, cultural, política e 
prática profissional, voltados para a melhoria da qualidade de vida humana e, como intelectuais, se apropriarem criticamente do conhecimento para não sucumbirem à lógica de mercado que vem se impondo em todos os setores e, notavelmente, na pós-graduação, com consequências fundamentais para a formação continuada

Os trabalhos que compõem a categoria 2, "Intervenção, Análise de programas e Políticas", são ao todo 31 estudos referentes a projetos, de cursos com acompanhamentos na escola, assessorias, propostas de práticas pedagógicas sobre conteúdos específicos da cultura corporal, formação de grupos de estudo e programas/políticas públicas já existentes de formação continuada, seja em nível municipal, estadual ou federal. Contudo, não se pode afirmar ao certo a formatação e qualidade de tais programa de formação continuada, posto que já denunciavam Miguel e Vieira (2008) que a disseminação da formação em serviço em sua forma mais barata (cursos de curta duração, à distância, etc.) pouco altera as reais condições de trabalho e remuneração, como também não garante mudanças significativas no processo pedagógico.

Como apontam Aguiar e Scheibe (2010), para que um programa de formação continuada seja significativo é necessário que os profissionais tenham tempo para trabalho coletivo e para a criação de novos projetos pedagógicos que envolvam os sujeitos da ação educativa na escola e na comunidade em que está inserida, além de garantia de financiamento público para a formação continuada (pós-graduação, grupos de estudos, programas de formação, entre outros).

Em relação aos trabalhos da terceira categoria "Sistema de Ensino Focado", obtivemos a constatação de que 23 trabaIhos foram direcionados à escola pública (ou sobre ela), 4 trabalhos às escolas privadas e 3 trabalhos referem-se aos ou de parceria público/privado. O fato dos pesquisadores direcionarem suas pesquisas para/ na escola pública pode ser um indicativo do compromisso com o ensino público e a melhoria da qualidade da educação nos moldes defendidos pelos movimentos dos educadores, centrada na concepção das múltiplas dimensões da formação humana, com o acesso gratuito como direito do cidadão e dever do Estado (PIMENTA; ANASTASIOU, 2014; SILVA JÚNIOR, 2002, SILVA JÚNIOR; SPEARS, 2012).

Paradoxalmente, como aponta Silva Júnior e Spears (2012), desde a década de 1990 como com a reestruturação econômica que vêm ocorrendo estabeleceu-se um precedente para as parcerias público-privadas e a universidade tem sido vista como uma importante estratégia para o crescimento econômico do país, colocando-a numa nova trajetória de reformas irreversíveis, isto porque a economia mais estável estabelecida no Brasil por meio do Plano Real possibilitou a privatização, expansão da classe média e a inovação (IDEM).

No entanto, na atual conjuntura, o questionamento do papel social da universidade pública brasileira tem colocado em perspectiva a sua importância no processo de qualificação, desenvolvimento e democratização da educação em oposição à universidade operacional que tem como princípio a economização universitária tal como colocada por Chauí (2001), Figueiredo (2013), Pimenta e Anastasiou (2014) dentre outros autores.

O eixo central constituinte da universidade deve ser revisto tomado pela 
indissociabilidade entre ensino-pesquisa-extensão, preparando-se para desempenhar o papel que corresponde às suas características que, no âmbito da educação, por sua vez, além do trabalho docente, seria de realizar pesquisas educacionais, didáticas, modelos alternativos de formação inicial e continuada, produzir subsídios para políticas públicas, integrando-se como parceira efetiva dos sujeitos inseridos no mundo do trabalho e na sociedade como um todo. Para isto há que se reconhecer o caráter político que envolve a docência, a postura crítica em relação à produção do conhecimento que é sempre provisório, inacabado e dinâmico e a intencionalidade de sua ação para as transformações rumo à emancipação social, pois, se a "educação retrata e reproduz a sociedade [...] também projeta a sociedade que se quer" (PIMENTA, 2002, p.17).

Neste sentido, destacamos que apesar de não ter sido o foco deste estudo, percebemos a carência de discussões acerca das temáticas supracitadas no referido GTT, tais como as reivindicações da classe, questões de carreira, salário, condições de trabalho, autonomia, tempo e espaço para se desenvolver profissionalmente, que se constituem em desafios ainda a serem enfrentados.

Por outro lado um dos trabalhos levantados neste estudo (SILVA; BANDEIRA, 2007) aponta para tais aproximações entre a formação inicial e continuada de professores no âmbito de Educação Física, a partir de iniciativas desenvolvidas em algumas universidades tais como Universidade Federal de Uberlândia-MG, Universidade Federal de Santa Catarina, Universidade Federal da Bahia, Universidade Federal do Espírito Santo, e propostas de capacitação de professores da rede pública pela Federal de Goiás, de São Paulo, dentre outras.

Nesse sentido, é compreensível que os dados levantados apontem para o interesse dos pesquisadores em realizar seus estudos no âmbito do ensino público.

\section{CONSIDERAÇÕES FINAIS}

Os debates e estudos sobre a formação inicial e continuada de professores em todas as áreas do conhecimento, dentre elas a Educação Física, têm apontado importantes reflexões sobre o trabalho docente e a necessidade da articulação deste com o mundo do trabalho, com a pesquisa, com a valorização e qualificação do profissional da educação em tempos de grandes mudanças advindas do mundo globalizado e de políticas neoliberais.

O objetivo deste artigo de investigar a produção científica em um evento nacional promovido por uma entidade científica representativa foi contemplado nos dados levantados e nas categorias estabelecidas para este estudo, dos quais as análises revelaram que há produção sistemática sobre o tema e que ocorre a articulação da pós-graduação com os problemas evidenciados, a preocupação com as políticas públicas e com a melhoria da prática pedagógica na educação física escolar e com a profissão docente. Contudo, como apontado, evidenciou-se algumas limitações diretamente relacionadas às condições do mundo do trabalho docente, carecendo de mais investigação sobre o tema.

A compreensão da relação entre educação e trabalho requer reconhecer que historicamente o professor, como proletário do ensino, foi destituído das condições de 
controle de seu próprio processo de trabalho e conduzido a uma desqualificação crescente sob as relações capitalistas, que reduziu cada vez mais sua parcela de responsabilidade no que se refere a pensar o processo de produção do ensino (FREITAS, 2007; SILVA JÚNIOR; SPEARS, 2012; PIMENTA; ANASTASIOU, 2014).

Neste sentido, como frisa Ribeiro (2003), faz-se necessário resgatar o professor como sujeito nesta relação, isto é, inserido em um contexto histórico, social, político, econômico, cultural, ideológico, capaz de fazer a leitura crítica da realidade para nela interferir tendo como pressuposto para o entendimento da docência, o reconhecimento da educação como uma produção histórica e social.

Este entendimento tem promovido uma inversão na lógica investigativa e na compreensão do mundo tal como tem sido preconizados pelos autores que trazem o professor como pesquisador, investigador, intelectual crítico-reflexivo e a educação como práxis. Nesta perspectiva, a formação continuada deve articular dialeticamente as diferentes dimensões da profissão docente que incluem os aspectos psicopedagógicos, técnicos, científicos, político-sociais, ideológicos, éticos e culturais (CANDAU, 1997).

É por este prisma que estudiosos da formação docente têm lutado, em consenso com a necessidade da formação teórica sólida, da unidade entre a teoria e prática, do compromisso social do profissional da educação, do trabalho coletivo e interdisciplinar como processo de reflexão, da educação como direito e como política pública que promova concretamente a sua universalização, que é o que se espera de uma sociedade realmente democrática.

\section{REFERÊNCIAS}

AGUIAR, M. A. S.; SCHEIBE, L. Formação e valorização: desafios para o PNE 2011/2020. In: Revista Retratos da Escola. Brasília, v.4, n.6, p.77-90,jan/ jul 2010.

ANDRADE FILHO, N. F. de. Formação profissional em educação física brasileira: uma súmula da discussão dos anos de 1996 a 2000. Rev. Bras.

Ciênc. Esporte, v. 22, n. 3, p. 23-37, maio 2001.

ANFOPE. Associação Nacional pela Formação de Profissionais da Educação. Políticas de Formação Inicial e Continuada de Profissionais da Educação no Contexto dos anos 2000. Documento Final do XV Encontro Nacional, Caldas Novas (MG), 2010.

. Associação Nacional pela Formação dos Profissionais da Educação. Políticas de formação e valorização dos profissionais da educação: $P N E$, Sistema Nacional na CONAE/2014 e Fóruns Permanentes de apoio à formação docente. Documento Final do XVI Encontro Nacional da Anfope, 2013. Brasília-DF, 2012. Disponível em: http://www.gppege.org.br/home/secao. asp?id_secao $=186$. Acesso em: 25 de outubro de 2014.

BIANCHETTI, L. 30 anos de Colégio Brasileiro de Ciências do Esporte: os desafios para uma associação científica e os dilemas dos intelectuais institucionalizados. Rev. Bras. Ciênc. Esporte Campinas, v. 30, n. 3, p. 1330, maio 2009.

BRACHT, V. et al. Educação física \& ciência: cenas de um casamento (in) feliz. Ijuí: Unijuí, 1999. 
BRASIL. Constituição (1988). Constituição da República Federativa do Brasil. Brasília, DF, Senado, 1998. Disponível em: < http://www.planalto.gov.br/ccivil_03/ constituicao/constituicao.htm > . Acesso em: 19 de dezembro de 2013.

. Lei $\mathrm{n}^{0}$ 5.692, de 11 de agosto de 1971. Fixa Diretrizes e Bases para o ensino de $1^{\circ}$ e $2^{\circ}$ graus, e dá outras providências. Brasília, 11 de agosto de 1971. Disponível em: <http://www. planalto.gov.br/ccivil_03/leis/l5692. $\mathrm{htm}>$. Acesso em $1 \overline{9}$ de dezembro de 2013.

. Lei $\mathrm{n}^{\circ}$ 9.394296, de 20 de dezembro de 1996. Estabelece as diretrizes e bases da educação nacional. Brasília, 20 de dezembro de 1996. Disponível em: http://www.planalto.gov.br/ccivil_03/ leis/l9394.htm. Acesso em 19/dez/2013.

. Lei no 10.172 , de 9 de janeiro de 2001. Aprova o Plano Nacional de Educação e dá outras providências. Brasília, 9 de janeiro de 2001. Disponível em: < http://www.planalto. gov.br/ccivil_03/leis/leis_2001/l10172. htm > . Acesso em: 19/dez/2013.

. Lei $n^{\circ} 12.796$, de 4 de abril de 2013. Altera a Lei no 9.394, de 20 de dezembro de 1996, que estabelece as diretrizes e bases da educação nacional, para dispor sobre a formação dos profissionais da educação e dar outras providências. Brasília, 4 de abril de 2013. Disponível em: < http://www. planalto.gov.br/ccivil_03/Ato20112014/2013/Lei/L12796.htm > . Acesso em: 18/dez/2013.

CANDAU, V. M. (Org). Magistério: construção cotidiana. Petrópolis: Vozes, 1997.

CAPES. Coordenação de Aperfeiçoamento Pessoal de Nível Superior. Mestrados/
Doutorados reconhecidos. Disponível em: < http://conteudoweb.capes.gov. br/conteudoweb/ProjetoRelacaoCur sosServlet?acao = pesquisarRegiao > Acesso em: 14/jan/2014.

CBCE. Congresso Brasileiro de Ciências do Esporte, 15. 2007. Salgadinho de Olinda. Anais eletrônicos... Salgadinho de Olinda. Disponível em: < http:// http://www.cbce.org.br/cd/lista area_06.htm > Acesso em: 08/jan/2014. . 16, 2009. Salvador. Anais eletrônicos... Salvador. Disponível em: http://www.rbceonline.org.br/congressos/ index.php/CONBRACE/XVI/schedConf/ presentations Acesso em: 08/jan/2014.

. 17, 2011. Porto Alegre. Anais eletrônicos... Porto Alegre. Disponível em: http://cbce.tempsite.ws/congressos/ index.php/XVII_CONBRACE/2011/ schedConf/presentations Acesso em: 08/jan/2014.

. 18, 2013. Brasília-DF. Anais eletrônicos... Disponível em: < http:// cbce.tempsite.ws/congressos/index. php/conbrace2013/5conice/schedConf/ presentations $>$ Acesso em: 08/ jan/2014.

CHAUÍ, M. Escritos sobre a universidade. São Paulo: UNESP, 2001.

DOURADO, L. F. A reforma do Estado e as políticas de formação de professores. In: PARO, V. H.; DOURADO, L. F. Políticas públicas \& educação básica. São Paulo: Xamã, p. 49-58, 2001. - Políticas e gestão da educação básica no Brasil: limites e perspectivas. Revista Educação e Sociedade, Campinas, v. 28, n. 100 - Especial, p. 921-946, out. 2007.

FAZENDA, I. C. A. (Org.). A pesquisa em educação e as transformações do 
conhecimento. $6^{\text {a }}$ Ed. Campinas, SP: Papirus, 2004.

FIGUEIREDO, A. C. A universidade pública brasileira sob o paradigma da pósmodernidade. Revista HISTEDBR On-line, Campinas, $n^{\circ}$ 49, p.137-148, mar. 2013.

FREITAS, H. C. L. Formação de professores no Brasil: 10 anos de embate entre projetos de formação. Educação e Sociedade, vol.23, n. 80. Campinas, setembro de 2002.

. A (nova) política de formação de professores: a prioridade postergada. In: Educação e Sociedade.v.28, n.100, Campinas, 2007.

FRIGOTTO, G. Educação e crise do trabalho: perspectivas de final de século. Petrópolis: Vozes, 2008.

GATTI, B. A. Análise das políticas para formação continuada no Brasil, na última década. Rev. Bras. De Educação. Vol. 13, n. 37. p.57-70, Abril/2008.

GÜNTHER, M. C. C.; MOLINA NETO, V. Formação permanente de professores de educação física na rede municipal de ensino de Porto alegre: uma abordagem etnográfica. Rev. paul. Educ. Fís., São Paulo, v.14, n.1, p.72-84, jan./jun. 2000.

KUENZER, A. Z. et al. Planejamento e educação no Brasil. São Paulo: Cortez/ Autores Associados, 1990.

LÜDKE, S. e ANDRÉ, M. Pesquisa em educação: abordagens qualitativas. São Paulo: EPU, 1986.

MARCELO GARCÍA, C.. Formação de professores: para uma mudança educativa. Porto: Porto, 1999.

MARCONI, M. A.; LAKATOS, E. $M$. Fundamentos de metodologia científica. 5 ed. São Paulo: Atlas, 2003.
MIGUEL,M.E.B. e VIEIRA,A.M.D.P. As políticas educacionais e a formação continuada do professor. In: Revista HISTEDBR On-Line, Campinas, n.31,p.127-141, set.2008.

MILESKI, K. G. et al. A produção científica nas teses e dissertações: formação de professores em Educação Física - 1987 a 2004. In: CONGRESSO BRASILEIRO DE CIÊNCIAS DO ESPORTE, 15, 2007, Pernambuco. Anais... Pernambuco, 2007, 11 p.

MINAYO, Maria C. S. (Org.). Pesquisa Social: teoria, método e criatividade. Petrópolis: Vozes, 1994.

MOLINA NETO, V; TRIVINÕS, A. N. S. (Orgs.). A pesquisa qualitativa na educação física: alternativas metodológicas. Porto Alegre: Ed Universidade/UFRGS/Sulina,1999.

NÓVOA, A. Formação de professores e profissão docente. In: NÓVOA, A. (Coord.). Os professores e a sua formação. Lisboa: Dom Quixote, p. 15-33, 1992.

PIMENTA, S. G., ANASTASIOU, L. G. C. Docência no ensino superior. 5 ed., São Paulo: Cortez, 2014.

PIMENTA, S. G. In: CONTRERAS, J. A autonomia dos professores. São Paulo: Cortez, 2002.

PIMENTA, S .G.; GHEDIN, E. (Orgs). Professor Reflexivo no Brasil: gênese e crítica de um conceito. São Paulo:Cortez,2002.

REVISTA BRASILEIRA DE CIÊNCIAS DO ESPORTE. Campinas, v.24,n.2,p.7-218, jan.2003.

RIBEIRO, D. M. D. B. A epistemologia da prática reflexiva na formação inicial do professor de educação física. 2003. 193 f. Dissertação (Mestrado em Educação) - Universidade Estadual de Maringá, Maringá, 2003. 
SACRISTÁN, J. C.; PÉREZ GÓMEZ, A. I. Compreender e transformar o ensino. Porto Alegre: Artes Médicas Sul, 1998.

SÁNCHEZ GAMBOA,S.A;CHAVES,M.;TA FFAREL,C.N. A pesquisa em Educação Física no Nordeste Brasileiro (Alagoas, Bahia, Pernambuco e Sergipe) de 1982-2004: balanço e perspectivas. In: Revista Brasileira de Ciências do Esporte, v.29, n.1, 2007.

SAVIANI, D. Escola e democracia. São Paulo: Cortes/Autores Associados, 1987.

SCHÖN, D. Educando o profissional reflexivo: um novo design para o ensino e a aprendizagem. Porto Alegre: Artes Médicas Sul, 2000.

SGUISSARDI, V. Políticas de Estado e Políticas de Educação Superior no Brasil: alguns sinais marcantes da dependência. In: MOROSINI, M. C. MERCOSUL/MERCOSUR: políticas e ações universitárias. Campinas: Autores Associados, p.205-231, 1998.

SILVA, H. L. F.; BANDEIRA, L. B. Mapeando a relação entre pesquisa e formação de professores de educação física. In: CONGRESSO BRASILEIRO DE CIÊNCIAS DO ESPORTE, 15, 2007,
Pernambuco. Anais... Pernambuco, 2007, 11 p.

SILVA JÚNIOR, J. R. Reforma do Estado e da Educação no Brasil de FHC. São Paulo: Xamã, 2002.

SILVAJÚNIOR, J.R; SPEARS, E. Globalização e a mudança do papel da universidade federal brasileira: uma perspectiva da economia política. Revista HISTEDBR On-line, Campinas, n. 47, p. 3-23, set. 2012.

TAFFAREL, C. N. Z. Política científica e produção do conhecimento na educação física/ciência do esporte: a conjuntura, as contradições e as possibilidades de superação. In: CARVALHO, Y. M.; LINHALES, M. A.(Orgs.). Política científica e produção de cnhecimento em educação física. Goiânia: CBCE, 2007.

TARDIF, M. Saberes docentes e formação profissional. Petrópolis, RJ: Vozes, 2002.

ZEICHNER, K. M. A formação reflexiva de professores, idéias e práticas. Lisboa: EDUCA, 1993.

SCIENTIFIC PRODUCTION IN CBCE/CONBRACE: the continuing education from 2007 to 2013 in focus

\section{ABSTRACT}

This study, qualitative and documentary character, aimed to analyze the scientific production about continuing education of teachers between the years 2007 and 2013, from the GTT "Teachers Training and the World of Work" of the Brazilian Sports Science College. We identified 49 papers about the issue, which were categorized into different groups based on their approaches and features. The results portray the existence of systematic scientific production about continuing education, and that is articulate with the reality of Brazilian graduate. However, some categories showed little representation, pointing challenges to be faced, requiring more research about the issue.

Keywords: Continuing Education; Physical Education; Knowledge; Work 
LA PRODUCCIÓN CIENTIFICA EN EL CBCE/CONBRACE: la formación continua de 2007 a 2013 en foco

\section{RESUMEN}

El presente trabajo, de y caracter documental Y cualitativo, buscó analizar la produción científica sobre formación continua de professores entre los años de 2007 y 2013, apartir del GTT "Formación de Profesores y el Mundo del Trabajo" del Colégio Brasileño de Ciencias del Deporte. Se identificó 49 trabajos sobre el tema, los quales fueron categorizados en distintos grupos, apartir de sus enfoques y características. Los resultados obtenidos retratan la existencia de la produción científica sistemática sobre la formación continua, y que esta se encuentra articulado con la realidad del pós-grado brasileña. Considerándolo todo, algunas categorías no demostraron grande representatividad, apuntando desafios a seren enfrentados, careciendo de mayor investigación sobre la temática.

Palabras clave: Formación Continua; Educación Física; Conocimiento; Trabajo

Recebido em: março/2015 Aprovado em: outubro/2015 